\title{
Nested polymerase chain reaction amplification and sequencing analysis of the light-chain and heavy-chain variable regions in the influenza A H1N1 virus hemagglutinin monoclonal antibody gene
}

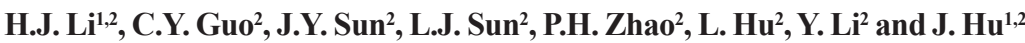 \\ ${ }^{1}$ School of Medicine, Xi'an Jiaotong University, Xi'an, Shaanxi, China \\ ${ }^{2}$ Central Laboratory of Shaanxi Provincial People's Hospital, Xi'an, \\ Shaanxi, China \\ Corresponding author: J. $\mathrm{Hu}$ \\ E-mail: huijin_li@yeah.net
}

Genet. Mol. Res. 13 (2): $4372-4379$ (2014)

Received June 12, 2013

Accepted October 4, 2013

Published June 11, 2014

DOI http://dx.doi.org/10.4238/2014.June.11.1

\begin{abstract}
The nested polymerase chain reaction (PCR) method was used for the amplification of the influenza A H1N1 virus hemagglutinin monoclonal antibody light-chain and heavy-chain genes. Sequence analysis of the obtained genes was then used to identify common cloning methods of the mouse immunoglobulinkappa (Igк) light-chain and heavy-chain variable gene regions. Twenty-two pairs of amplification primers for the mouse Igא lightchain and heavy-chain variable gene regions were designed, and 6 mouse anti-human H1N1 influenza virus hemagglutinin monoclonal antibody light-chain and heavy-chain variable gene regions were cloned and sequenced. Comparative analysis was conducted between our results and the mouse Ig sequences published in the National Center of Biotechnology Information (NCBI). The nested PCR method effectively avoided cloning the pseudogenes of the
\end{abstract}


monoclonal antibody, and the amino acid sequence obtained was consistent with the characteristics of the mouse Ig variable region. A general method of cloning the mouse Ig light-chain and heavy-chain variable gene regions was established, which provides a basis for further cloning of mouse monoclonal antibody variable gene regions. This study also provides data for further studies of H1N1 influenza virus hemagglutinin antibody binding sites.

Key words: Influenza A (H1N1) virus; Monoclonal antibody; Variable region; Nested PCR; Sequence analysis

\section{INTRODUCTION}

The new strain of influenza A (H1N1) is an acute respiratory infectious disease that is caused by a novel recombinant virus from three sources: humans, pigs, and poultry. It is characterized by its general population susceptibility, rapid onset, rapid spread, and serious complications (Michaelis et al., 2009; Hauge et al., 2009; Naffakh and van der Werf, 2009; Peiris et al., 2009). Influenza A (H1N1) has yielded substantial negative impacts on global human health and economic development. Vaccination has became the most effective means of preventing the outbreak of new influenza A, but a small number of adverse events after vaccination have led to questioning the safety of the vaccination (Greenberg et al., 2009; Wu et al., 2010; Moro et al., 2011; Baras et al., 2011). The main component of the current vaccination is the hemagglutinin protein of the H1N1 influenza virus. Further study of the influenza virus hemagglutinin protein structure will result in identification of the amino acid sites of the antigenic determinant, subsequent flu vaccine transformation, and the safety of the flu vaccine. This study focused on the monoclonal antibodies of H1N1 influenza virus hemagglutinin. We used the nested polymerase chain reaction (PCR) method, and amplified and sequenced the variable gene regions of the antibody light chain and heavy chain from hybridoma cells that secrete the influenza antibodies. This study will provide a basis and experimental evidence for further analysis of antibodies and antigen-binding targets.

\section{MATERIAL AND METHODS}

\section{Materials}

The Escherichia coli DH5 $\alpha$ strain was maintained in our laboratory, and 6 H1N1 influenza virus hemagglutinin monoclonal antibodies, A1-6, A1-8, A1-12, H1-4, H1-13, and $\mathrm{H} 1-28$, were also prepared in our laboratory. The subtype of the antibody light chain was the $\kappa$ chain. The total RNA extraction kit was purchased from the Tiangen Biotech Company (Beijing, China). ExTaq polymerase, rTaq polymerase, restriction enzymes, the pMD19-T carrier, and the DNA Marker were purchased from Dalian TaKaRa. The reverse transcription kit, plasmid extraction kit, and DNA gel extraction kit were purchased from Tiangen. Isopropyl- $\beta$-D-1-thiogalactopyranoside (IPTG), X-Gal, and ampicillin were purchased from Sigma (USA). Primer synthesis and sequencing were carried out by the Beijing Liuhe Huada Genomics Technology Co., Ltd.; all other reagents were of analytical 
grade. The Fluor Chem FC2 gel imaging system was purchased from the Alpha Innotech Corporation (USA).

\section{Total RNA extraction and cDNA synthesis}

The hybridoma cell lines that secreted the antibody were cultured, and the well-grown hybridoma cells were collected. Approximately $1 \times 10^{6}$ cells $/ \mathrm{mL}$ were collected. Total RNA was extracted with the Tiangen total RNA extraction kit. The extracted RNA was taken as the template, and the cDNA was synthesized according to instructions of the Tiangen cDNA first-strand kit.

\section{Primer design of the variable gene regions of the antibody light chain and heavy chain}

The nucleotide sequences of the light-chain and heavy-chain variable gene regions of immunoglobulin kappa (Igא) in the mouse antibody Kabat database were compared for primer design. For the 6 families of the light chain, we designed seven pairs of amplification primers in the $\mathrm{V}_{\mathrm{L}}$ light-chain variable region. The upstream design began from the FWR1 region, and primers P1-P7 were designed. The downstream design ended in the FWR4 region, and the universal primer P8 was designed. According to the heavy-chain gene from 5 families, 5 pairs of primers were designed for the amplification of $\mathrm{V}_{\mathrm{H}}$. The upstream primer began in the FWR1 region, and primers P9-P13 were designed. The downstream primer ended in the FWR4 region, and primer P14 was designed. The specific sequence and family classification of the identification primers are shown in Table 1. Five pairs of light-chain identification primers were designed: P1-P15, P2-P16, P3-17, P4-17, P5-P18, and P7-P19. The upstream primers started from the FWR1 region, and the downstream primers reached amino acids 55 to 63 in the FWR3 region. The specific sequence and family classification of the lightchain identification primers are shown in Table 2. Five pairs of heavy-chain identification primers were designed: P20-P14, P21-P14, P22-14, P23-14, and P24-P14. The upstream region started from amino acids 66 to 72 in the FWR3 region, and the downstream region reached the FWR4 region. The specific sequence and family classification of the heavy-chain identification primers are shown in Table 3. All primers were synthesized by the Beijing Liuhe Huada Genomics Technology Co., Ltd.

\begin{tabular}{|c|c|c|}
\hline Antibody family & Primers & Sequence $\left(5^{\prime}-3^{\prime}\right)$ \\
\hline I & P1 & GACATTGTGATGWCACAGTCTCC \\
\hline II & P2 & GATRTTKTGATGACYCARRCTCC \\
\hline III-1 & P3 & GACATTGTGCTGACCCAATCTCC \\
\hline III-2 & P4 & GACATTGTGCTGACACAGTCTCC \\
\hline IV\&VI & P5 & SAAAWTGTKCTCACCCAGTCTCC \\
\hline $\mathrm{V}-1$ & P6 & GAYATYMAGATGACMCAGWC \\
\hline $\mathrm{V}-2$ & P7 & GAYATTGTGATGACMCAGWCT \\
\hline $\mathrm{I} \sim \mathrm{VI}$ & P8 & TTTBAKYTCCAGCTTGGTSCC \\
\hline IA\&IB & P9 & AGGTGCAGCTKMAGGAGTCAGG \\
\hline IIA\&IIB\&VA & P10 & AGGTYCAGCTKCARSARTCT \\
\hline IIB & P11 & AGGTCCARCTGCAGCAGYCT \\
\hline IIIA\&IIIC\&IIID & P12 & AGGTGMAGCTKGWGGARTCTGG \\
\hline IIIB & P13 & AGGTGAAGCTTCTCGAGTCTGG \\
\hline $\mathrm{I} \sim \mathrm{V}$ & P14 & TGAGGAGACGGTGACCGTGGTCCCTTGGCCCC \\
\hline
\end{tabular}


Table 2. Primers of the light-chain variable gene regions.

\begin{tabular}{lcl}
\hline Antibody family & Primers & Sequence $\left(5^{\prime}-3^{\prime}\right)$ \\
\hline I & P15 & TRTGAAGCGATCAGGGAC \\
II & P16 & ASTGAACCTGTCTGRGACYCC \\
III & P17 & ACTRAACCTGGCAGGGAY \\
IV \&V-2\&VI & P18 & ACTGAASCGAKCWGGGACTCC \\
V-1 & P19 & GAACCTTGATGGGACTCC \\
\hline
\end{tabular}

\begin{tabular}{lcl} 
Table 3. Primers of the heavy-chain variable gene regions. \\
\hline \\
\hline Antibody family & Primers & \\
\hline IA & P20 & Sequence $\left(5^{\prime}-3^{\prime}\right)$ \\
IB & P21 & ATCCGWGACACATCYAAGAAC \\
IIA\&IIB\&IIC & P22 & ATCAGCAAAGACAACTCCAAGA \\
IIIA\&IIIB\&IIIC\&IIID & P23 & AAGGCCACWWTVACWGYMGA \\
VA & P24 & MRRTCAYCRTCTCMAGAG \\
\end{tabular}

\section{Cloning of the antibody light-chain and heavy-chain variable gene regions}

The extracted cDNA was taken as the template, and the designed primers P1-P8 were used to amplify the light-chain variable gene region of the antibody, whereas primers P9-P14 were used to amplify the heavy-chain variable gene region. The same PCR system and amplification conditions were applied to the light-chain and heavy-chain variable gene regions. The 25- $\mu \mathrm{L}$ PCR system was as follows: 10X Ex Buffer with $2.5 \mu \mathrm{L} \mathrm{Mg}^{2+}, 2 \mu \mathrm{L} 2.5 \mathrm{mM}$ of each $\mathrm{dNTP}, 1 \mu \mathrm{L} 20 \mu \mathrm{M} \mathrm{P}_{\mathrm{F}}, 1 \mu \mathrm{L} 20 \mu \mathrm{M} \mathrm{P}_{\mathrm{D}}, 0.3 \mu \mathrm{L}$ Ex Taq polymerase, $1 \mu \mathrm{L}$ cDNA, and $17.2 \mu \mathrm{L}$ distilled water. The PCR conditions were as follows: $94^{\circ} \mathrm{C}$ for $5 \mathrm{~min}, 94^{\circ} \mathrm{C}$ for $30 \mathrm{~s}, 55^{\circ} \mathrm{C}$ for 30 $\mathrm{s}, 72^{\circ} \mathrm{C}$ for $30 \mathrm{~s}$, for a total of 30 cycles, and $72^{\circ} \mathrm{C}$ for $10 \mathrm{~min}$. The PCR-amplified light-chain variable gene region was identified by nested PCR with corresponding identifying primers (the positive target band size was about $180 \mathrm{bp}$ after the light-chain identification, and the positive target band size was about 150 bp after the heavy-chain identification). Then, the PCR amplified light-chain and heavy-chain variable gene region fragments were obtained on the gel, and were combined with the pMD19-T carriers according to kit instructions. The combined products were transformed into $E$. coli DH5 $\alpha$ competent cells, and 6 to 8 clones were selected to conduct bacterium liquid PCR and plasmid restriction enzyme digestion identification.

\section{Colony PCR identification of target gene fragments}

PCR was used to amplify the target band under the following program: $94^{\circ} \mathrm{C}$ denaturation for $5 \mathrm{~min}, 94^{\circ} \mathrm{C}$ denaturation for $30 \mathrm{~s}, 55^{\circ} \mathrm{C}$ annealing for $30 \mathrm{~s}, 72^{\circ} \mathrm{C}$ extension for 30 s for 30 cycles, and $72^{\circ} \mathrm{C}$ extension for $10 \mathrm{~min}$. The reaction volume was $10 \mu \mathrm{L}$, and $1.5 \mathrm{~g} / \mathrm{L}$ agarose gel electrophoresis was used for identification of the PCR products.

\section{DNA sequencing and analysis}

The positive clones were identified and sent to the Beijing Huada Genomics Institute 
for sequencing. DNAMAN and BLAST softwares were used to compare and analyze the sequencing results.

\section{RESULTS}

\section{Cloning of antibody light-chain and heavy-chain variable gene regions}

The reverse transcribed-PCR synthesized cDNA was taken as the template, and the 12 pairs of antibody light-chain and heavy-chain variable gene region primers were used for PCR amplification of 6 antibodies. Finally, using different primers, we successfully amplified the target gene from various cell lines secreting hybridomas. The corresponding primers after the successful amplification of each antibody are shown in Table 4. The PCR products were identified with $1.5 \%$ agarose gel electrophoresis, and the results are shown in Figure 1 . The length of the variable gene region of the light chain $\left(\mathrm{V}_{\mathrm{L}}\right)$ was approximately $320 \mathrm{bp}$, and that of the variable region of the heavy chain $\left(\mathrm{V}_{\mathrm{H}}\right)$ was approximately $350 \mathrm{bp}$.

Table 4. PCR primers of light-chain and heavy-chain variable regions of each antibody.

\begin{tabular}{lcc}
\hline Antibody & $\mathrm{V}_{\mathrm{L}}$ primer & Vh primer \\
\hline A1-6 & P7-P8 & P12-P14 \\
A1-8 & P7-P8 & P12-P14 \\
A1-12 & P3-P8 & P12-P14 \\
H1-4 & P2-P8 & P9-P14 \\
H1-13 & P3-P8 & P12-P14 \\
H1-28 & P2-P8 & P10-P14 \\
\hline
\end{tabular}

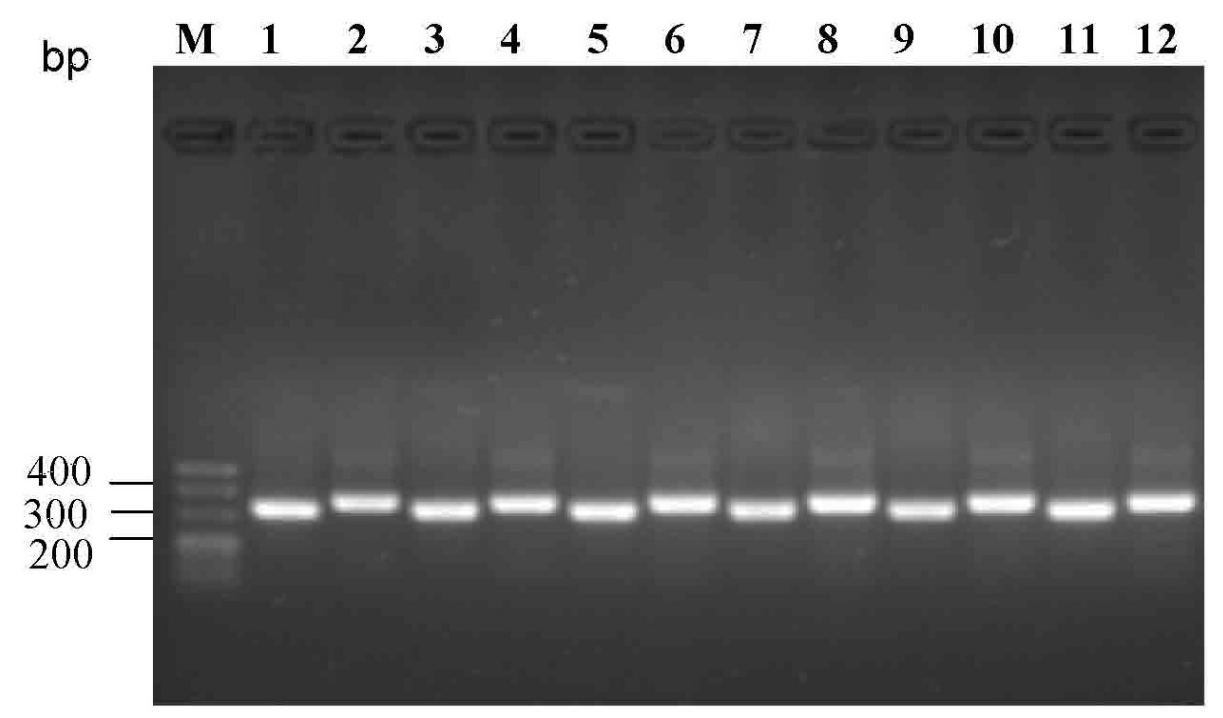

Figure 1. PCR products of 6 antibody light-chain and heavy-chain variable gene regions. Lane $M=$ DL500 marker; lane $1=\mathrm{A} 1-6 \mathrm{~V}_{\mathrm{L}}$; lane $2=\mathrm{A} 1-6 \mathrm{~V}_{\mathrm{H}}$; lane $3=\mathrm{A} 1-8 \mathrm{~V}_{\mathrm{L}}$; lane $4=\mathrm{A} 1-8 \mathrm{~V}_{\mathrm{H}}$; lane $5=\mathrm{A} 1-12 \mathrm{~V}_{\mathrm{L}}$; lane $6=\mathrm{A} 1-12 \mathrm{~V}_{\mathrm{H}}$; lane $7=\mathrm{H} 1-4 \mathrm{~V}_{\mathrm{L}}$; lane $8=\mathrm{H} 1-4 \mathrm{~V}_{\mathrm{H}}$; lane $9=\mathrm{H} 1-13 \mathrm{~V}_{\mathrm{L}}$; lane $10=\mathrm{H} 1-13 \mathrm{~V}_{\mathrm{H}}$; lane $11=\mathrm{H} 1-28 \mathrm{~V}_{\mathrm{L}}$; lane $12=\mathrm{H} 1-28 \mathrm{~V}_{\mathrm{H}}$. 


\section{Antibody $V_{L}$ and $V_{H}$ gene cloning and screening}

The antibody light-chain and heavy-chain variable gene regions were cloned into pMD19-T carriers. Bands corresponding to the size of the target fragments were obtained after colony PCR and plasmid-extracted restriction enzyme digestion identification.

\section{Antibody light-chain and heavy-chain variable gene region sequence analysis}

From the amplified antibody light chains, 4 to 6 positive clones were selected and sequenced, and 3 to 4 positive clones were sequenced from the heavy chains. The sequencing results were compared with the NCBI BLAST Ig database; 6 of the antibody light-chain and heavy-chain variable gene regions were consistent with the characteristics of mouse Ig variable gene regions. The A1-6 sequence is shown as a representative example in Figure 2. The total length of the A1-6 $\mathrm{V}_{\mathrm{L}}$ sequence was $333 \mathrm{bp}$, and it encoded 111 amino acids. The total length of the A1-6 $\mathrm{V}_{\mathrm{H}}$ sequence was $339 \mathrm{bp}$, and it encoded 113 amino acids. The 23-bit and 93-bit of the light chain and the 21-bit and 95-bit of the heavy chain were Cys. One disulfide bond was formed in each chain, and the disulfide bond played an important role in the threedimensional structure formation of the antibody variable region. The corresponding antibody FWR and CDR regions are marked in Figure 2. Further analysis of the results showed that A1-6 $\mathrm{V}_{\mathrm{L}}$ belong to the subgroup $\mathrm{V}$ subtype and A1-6 $\mathrm{V}_{\mathrm{H}}$ belong to the subgroup III subtype.

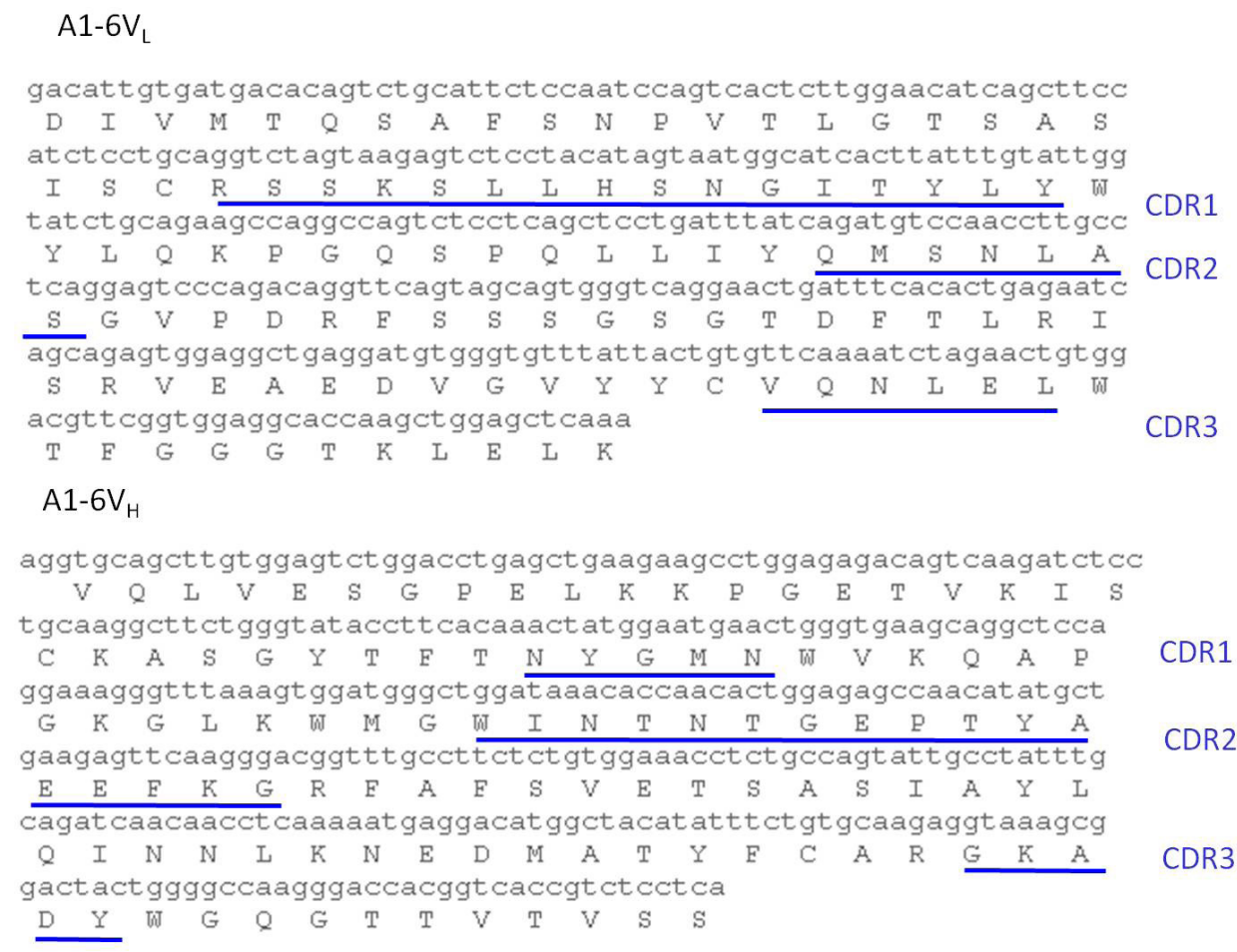

Figure 2. A1-6 sequences of antibody light-chain and heavy-chain variable gene regions. 


\section{DISCUSSION}

There are various possible methods available for amplification of the antibody gene. The key to successful amplification lies in the primer design, such as primers based on the leader peptide sequence and $\mathrm{J}$ sequence and family sequence primers for the conserved sequence in accordance with gene family classification (Liu et al., 1996). We compared and analyzed the gene sequences of the mouse Igא light-chain and heavy-chain variable regions available in the Kabat database, according to the gene family classification and analysis of sequence conservation of each family antibody. Based on the conservative sequence of the FWR1 and FWR4 regions, we designed 12 pairs of primers according to the light-chain variable gene region of 6 families, and we designed a further 10 pairs of primers according to the heavy-chain variable gene region of 5 families. Our experimental results showed that 12 pairs of amplification primers achieved good results in the amplification of the antibody gene from 6 specific hybridoma cells. We used the primers to successfully clone multiple strains of other mouse monoclonal antibody light-chain and heavy-chain variable gene regions. Therefore, the set of primers designed herein can be regarded as universal primers for PCR amplification of the light-chain and heavy-chain variable gene regions of the mouse monoclonal antibody. These primers will help to resolve some challenges in monoclonal antibody gene cloning, particularly for the light-chain variable gene region.

According to clonal selection theory, immunoreactive cells can clone with a variety of existing receptors, and the role of the antigen is to select and activate the corresponding clone. One kind of hybridoma cell only secretes a specific functional monoclonal antibody. In this study, the total cellular RNA was reverse transcribed to produce the cDNA template, and the specific $\mathrm{V}_{\mathrm{L}}$ and $\mathrm{V}_{\mathrm{H}}$ gene segments were obtained with PCR amplification. During $\mathrm{V}_{\mathrm{L}}$ gene amplification, although specific bands were amplified, we found that the band size in some parts of the gene was the same as that of the target fragments. The sequencing results showed that the Cys on the 23-bit of the FWR1 region was mutated into Tyr. Li et al. (2008) extracted total RNA of SP2/0 myeloma cells, reverse transcribed it into cDNA, and the light-chain variable gene region was amplified using different primers. The obtained light-chain variable gene region sequences only had one cysteine residue, and the three-dimensional structure of the variable region, which was built with intra-chain disulfide bonds, could not be formed (Li et al., 2008). In the present study, in order to avoid the amplification of a large number of pseudogenes in the light-chain PCR, appropriate primers were designed for each family. The PCR variable gene region was identified by PCR and identifying primers, indicating that this nested PCR method can reduce the proportion of amplified light-chain pseudogenes.

Our previous studies have shown that the flu vaccination is effective (Wu et al., 2010; Baras et al., 2011), which can enhance the immunity of susceptible populations and can form an effective immune barrier to prevent the spread of H1N1. However, questions remain as to the safety of the vaccine. In this study, we successfully cloned 6 influenza A H1N1 hemagglutinin monoclonal antibody light-chain and heavy-chain variable gene regions. These results may provide experimental data for further analyses of the influenza virus antigen and antibody binding sites, the vaccine's safety, and engineering of the human endogenous antibody gene.

\section{ACKNOWLEDGMENTS}

Research supported by the Natural Science Foundation of China (Grant \#81202373). 


\section{REFERENCES}

Baras B, de Waal L, Stittelaar KJ, Jacob V, et al. (2011). Pandemic H1N1 vaccine requires the use of an adjuvant to protect against challenge in naive ferrets. Vaccine 29: 2120-2126.

Greenberg ME, Lai MH, Hartel GF, Wichems CH, et al. (2009). Response to a monovalent 2009 influenza A (H1N1) vaccine. N. Engl. J. Med 361: 2405-2413.

Hauge SH, Dudman SG, Borgen K, Hungnes O, et al. (2009). Disease caused by the new influenza A(H1N1) virus. Tidsskr. Nor Laegeforen. 129: 1736-1739.

Li YY, Yang D and Bian ZP (2008). Mouse anti-human cTnI monoclonal antibody Fab-gene cloning and sequence analysis. Di Si Jun Yi Da Xue Xue Bao 29: 785-787.

Liu XF, Xiao F and Gu Z (1996). Anti-human CD3 monoclonal antibody light and heavy chain variable region gene cloning and sequence analysis. Sheng Wu Gong Cheng Xue Bao 12: 116-120.

Michaelis M, Doerr HW and Cinatl J Jr (2009). Novel swine-origin influenza A virus in humans: another pandemic knocking at the door. Med Microbiol. Immunol. 198: 175-183.

Moro PL, Broder K, Zheteyeva Y, Walton K, et al. (2011). Adverse events in pregnant women following administration of trivalent inactivated influenza vaccine and live attenuated influenza vaccine in the Vaccine Adverse Event Reporting System, 1990-2009. Am. J. Obstet. Gynecol. 204: 146-147.

Naffakh N and van der Werf S (2009). April 2009: an outbreak of swine-origin influenza A(H1N1) virus with evidence for human-to-human transmission. Microbes Infect. 11: 725-728.

Peiris JS, Poon LL and Guan Y (2009). Emergence of a novel swine-origin influenza A virus (S-OIV) H1N1 virus in humans. J. Clin. Virol. 45: 169-173.

Wu J, Xu F, Lu L, Lu M, et al. (2010). Safety and effectiveness of a 2009 H1N1 vaccine in Beijing. N. Engl. J. Med. 363: 2416-2423. 